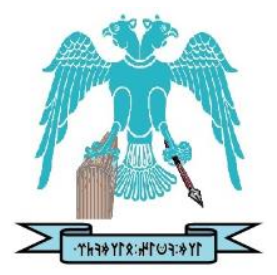

JOURNAL OF ENERGY SYSTEMS

2022, 6(1)

\title{
An analysis on mode excitation energy in beam-like structures
}

\author{
Tark Tufan \\ İstanbul Medeniyet University, Ünalan, Üsküdar, İstanbul, Turkiye, tarik.tufan@medeniyet.edu.tr \\ Hasan Köten \\ İstanbul Medeniyet University, Ünalan, Üsküdar, İstanbul, Turkiye, hasan.koten@ medeniyet.edu.tr
}

Abstract: Energy harvesting, which is a popular subject, can be defined as the use of energy released by environmental forces such as earth-shaking, wind, etc. Civil engineering structures also harvest energy in a different way. Thanks to this energy harvest, the modal properties of structures such as natural frequency, mode shape can be estimated from the response histories taken from the structure. Modal properties of the structure give an impression of the health of the building. However, an important question comes to mind: Did the energy harvesting of the structures sufficiently drive the modes used to detect damage? Or in other words, has it exceeded a certain amount of energy to drive the modes? If the mode in question is not sufficiently excited, it can be interpreted as a harbinger of damage for an undamaged structure in the analysis using these modes. For this reason, it is an important issue to determine to what extent the modes are driven. In this study, the aforementioned subject has been explored with the title "Mode Excitation Energy" using the modal plot method.

Keywords: Energy harvesting, Modal plot, Mode excitation energy

Cite this paper Tufan T., \& Köten H., An analysis on mode excitation energy in beam-like structures. Journal as: of Energy Systems 2022; 6(1): 84-96, DOI: 10.30521/jes.952837

(c) 2022 Published by peer-reviewed open access scientific journal, JES at DergiPark (https://dergipark.org.tr/en/pub/jes)

\begin{tabular}{r|l} 
Nomenclature & \\
\hline DOF & Degree of Freedom \\
FFT & Fast Fourier Transform \\
FRF & Frequency Response Function \\
SHM & Structural Health Monitoring \\
\hline \hline
\end{tabular}




\section{INTRODUCTION}

Monitoring the health and determining the health status of each building in the building stock of a zone is an important issue to minimize the vulnerability parameter in the risk definition in the mitigation step of disaster management [1].

Thousands of bridges in the US are damaged or at risk of failure [2], and Japan will face the same situation in a few years [3]. In addition, damage caused by earthquakes [4], a tsunami [5], typhoon, or hurricane [6] will reduce the useful life of buildings. Therefore, it is crucial to install early warning systems to monitor and control therefore to assess the health of important structures. In many countries such as Japan [7] and Australia [8], SHM systems are widely used in critical structures and the necessary software and hardware components are developed by these countries. This issue is taken into consideration and its popularity is increasing day by day also in Istanbul [9] and in the world [10-17].

The health of a structure can be assessed according to the change in the modal properties of the system. However, the reason for this change can be both structural damage in the structure or changes in environmental conditions. Theoretically, the change in the natural frequency of the structure is defined as the change in the stiffness of the structure or damage to the structure in cases where there is no change in the mass of the structure and in environmental conditions such as temperature, and humidity.

The structures absorb the surrounding energy at any moment and transform it into unique vibrations that express characteristics of structure and the input force (Fig. 1). In fact, there is a relation between response spectrum and input spectrum of data taken on a system that is related to the system transfer function. This expression is formulated in Equation [1]:

$$
Y(j w)=H(j w) U(j w)
$$

where $Y(s)$ is output spectrum or Fourier transforms of the response, $U(s)$ is frequency response or Fourier transforms of the input force, and $H(s)$ is the transfer function [18].

In the white noise assumption, the input forces excite all frequency ranges on consideration 'equally' [19-21]. Thanks to the white noise assumption without the input force information, modal parameters of the structure can be estimated under operational conditions [22].

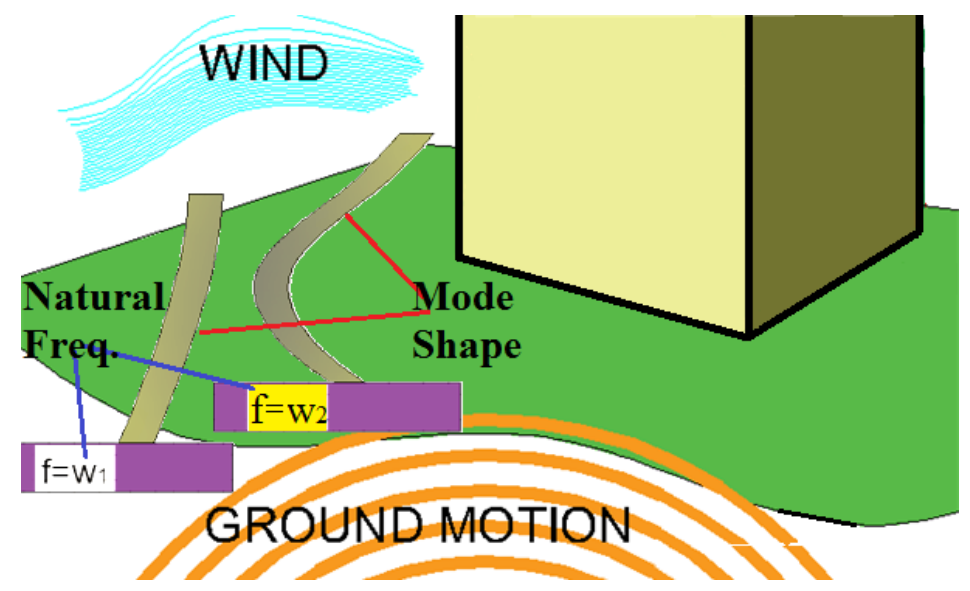

Figure 1. Energy harvesting of a structure 
If environmental energy is not harvested adequately, vibrations that give information about the properties of the structures do not occur. Because, as can be seen from equation 1, if there is no input force or the frequency band of the input force is not proper, there is no response (in that frequency range), and the transfer function, which expresses the properties of the structure, cannot be determined (in that frequency range).

In theory, modal analysis is a process defining the inherent dynamic characteristics of an object depending on the material and its geometry in terms of its resonant frequencies, mode shapes, damping factors, and modal scaling factors without the need of a disturbing force. The modal data are used to formulate the (mathematical) modal model of the object for its dynamic behavior [23]. In practice, due to irregularities in the characterization of a structure [24], location of excitation [25], input frequency content, the structure has not received sufficient energy to excite all the modes properly [26-28]. Also, there are problems related to scaling in the mode shape estimation and narrow-banded frequency content of the input forces [29] where Operational Modal Analysis (OMA) methods are insufficient. To address these problems, researchers have developed methods based on the combined experimental and operational modal analysis called Operational Modal Analysis with eXogenous inputs (OMAX) [30-32]

To approach the damage detection and system identification problem correctly, it should be clearly shown that the operational forces cannot drive the modes in the desired frequency range therefore OMA methods are inadequate and OMAX methods should be used. Then utilization and placement of shaker would arise. In that case, it is very important to place the shaker correctly so that the shaker can excite all the desired modes without damaging the structure. It is usually decided whether the modes are driven or not based on the "Frequency Response Function (FRF)" peaks. However, it is a very controversial issue that this method can answer such an important step. In this study, as an alternative to FRF, the modal plot [33] shows whether the defined input force can activate the modes sufficiently. To our best knowledge, there is no such alternative technique to FRF used to detect the mode excitation energy in the literature. Therefore, the proposed method presents a kind of novel approach to the literature and information in the field of SHM.

\section{SYSTEM IDENTIFICATION}

In the structural health monitoring (SHM) procedure, after receiving data such as acceleration, velocity, and displacement from the structure, the first step to be taken is to identify the system. In general, it is desired to estimate modal information of the system using frequency or time-domain methods. Many frequencies and mode shape estimates are subjected to screening and it is desired to calculate the closest "true" mode shape and natural frequency of the system. While the stabilization diagrams aim to accomplish this task with various elimination steps, the modal plot aims to construct modal points and modal regions without an elimination step.

\subsection{Modal Plot}

Modal plot is the name given to a graph where estimates of the mode shape and frequency of a system under an ambient input force are shown simultaneously according to a DOF. The natural frequencies of the system and the mode shape values corresponding to those frequencies appear in the modal plot as a modal point. Generally, damage information is tried to be calculated using only these mode points. modal Plots additionally show modal zones other than modal points. The modal zone is an important feature that is eliminated as noise in the literature, but shown to be associated with modal points and provides information about the input force. A representative modal plot is shown in Fig. 2. In short, the modal plot consists of (1) Modal points expressing natural frequencies and mode shape pair of the system and (2) a damage sensitive feature, which is the modal zone [33]. Even if modal points are not included in the modal zone, they remain quite close to it (Fig. 3). 


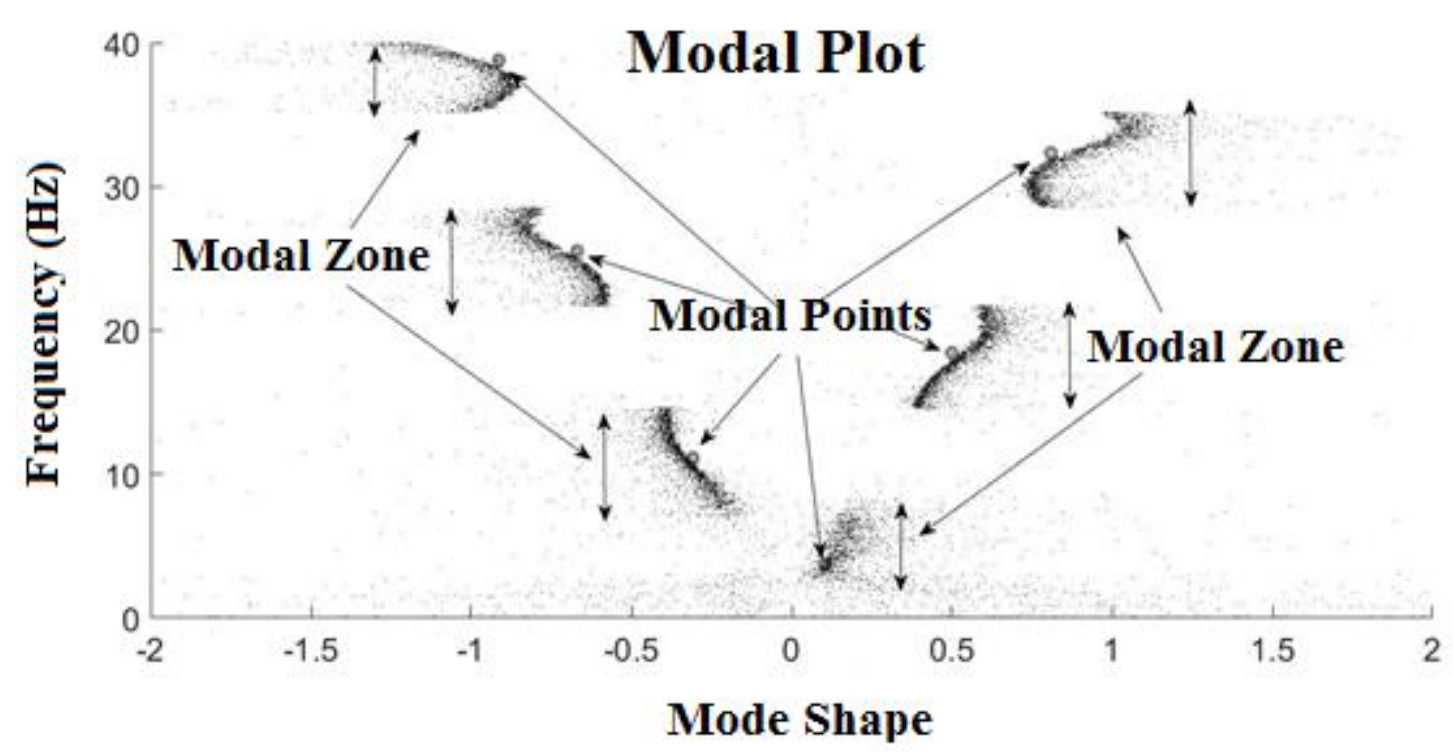

Figure 2. A representative modal plot.
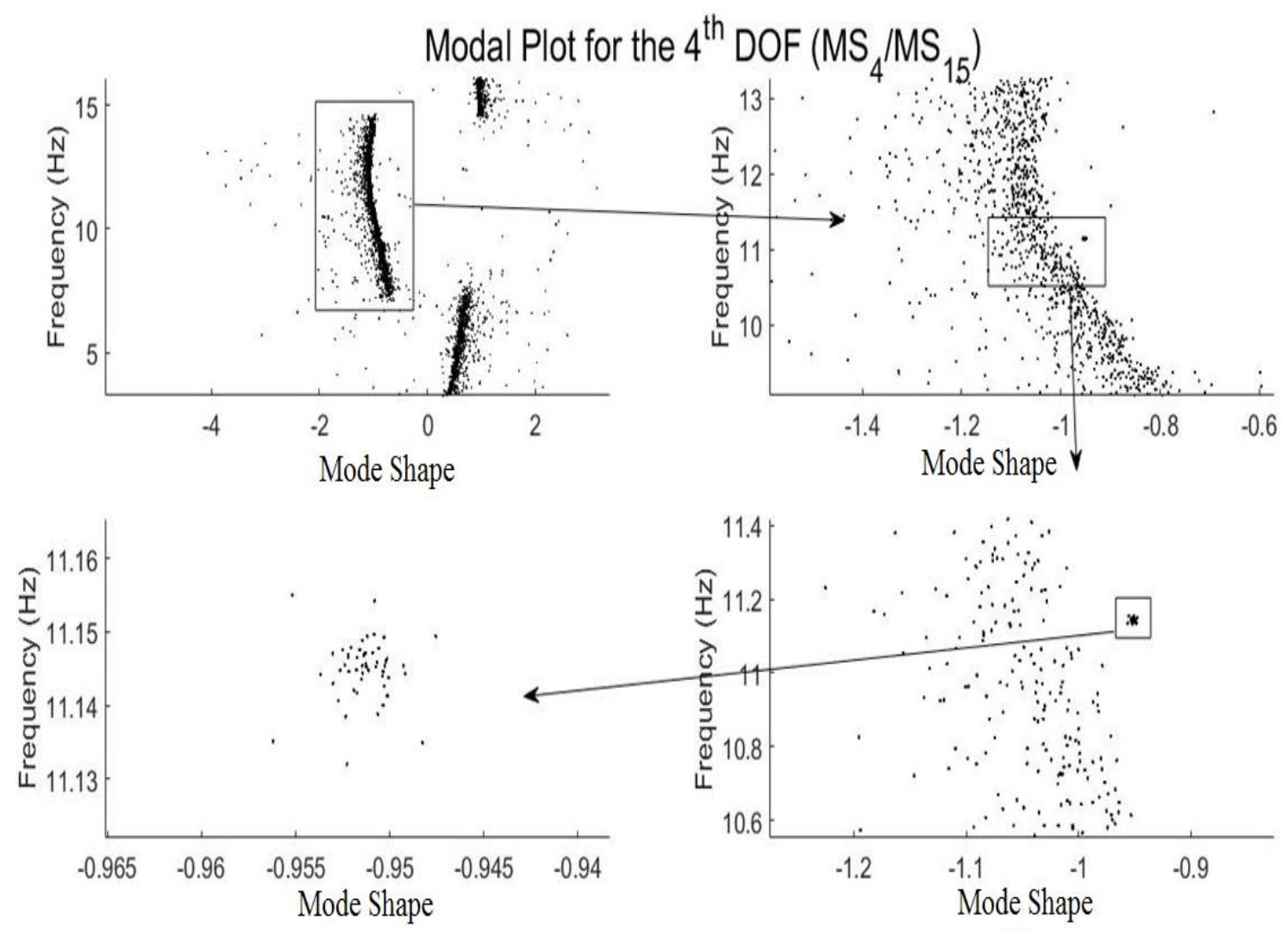

Figure 3. Modal point.

Modal zones can be converted to lines by using clustering methods. In this study, modal zones were converted into curves with the K-Means Clustering [34, 35] method, which is one of the popular methods in clustering. In the $\mathrm{k}$-means method, $\mathrm{m}$ points/estimates with $\mathrm{n}$ dimensions are decomposed into $\mathrm{k}$ clusters; so that difference of squares within the cluster is minimized [36]. 


\section{SIMULATION}

\subsection{The Mode Excitation Energy}

The numerical first case study is aimed at determining modal excitation energy with a modal plot. For this purpose, a fixed mass-spring model with 6 translational DOF with one free end and one free end has been investigated. In the piecewise system, all mass values are defined as equal and $1 \mathrm{~kg}$ and stiffness values equal and $14000 \mathrm{~N} / \mathrm{m}$. Primarily, the free-end, which is the 6th DOF, was chosen as a reference DOF. In the analyzes, the DOF's were examined in pairs together with the reference DOF one by one. Five-minute acceleration data taken from each DOF and sampled at $200 \mathrm{~Hz}$ were analyzed into 22second data segments with $88 \%$ overlap. It was observed that the responses did not have a timedependent slope, and only seven-second data averages were subtracted from it. The data were analyzed with $2933 \times 2933$ sized Hankel matrices and modal plots were built with the first 390 mode variable, which was seen to correspond to the $0-40 \mathrm{~Hz}$ frequency range that includes all modes. These procedures were repeated six times where force was applied from all DOFs in turn.

The Fig. 4 consists of 3 sub-graphs. Two modal plots are showed on top of each other in each subgraph. In the first sub-graph, first of all, the ambient force was applied from the 1st DOF and the modal plot was drawn, then the white noise was again applied from only the 4th DOF and again the modal plot was added. Similarly, white noise was applied separately from the 2nd and 5th DOF in the 2nd subgraph, and from the 3rd and 6th DOF in the last subgraph. From the 2nd graph of all sub-figures, we can draw the following 2 conclusions: Modal plots were drawn according to forces exerted by different degrees of freedom 1) pass quite close to modal points and 2) modal graphs drawn according to different force action points intersect at modal points. These two features are important for system identification purposes.

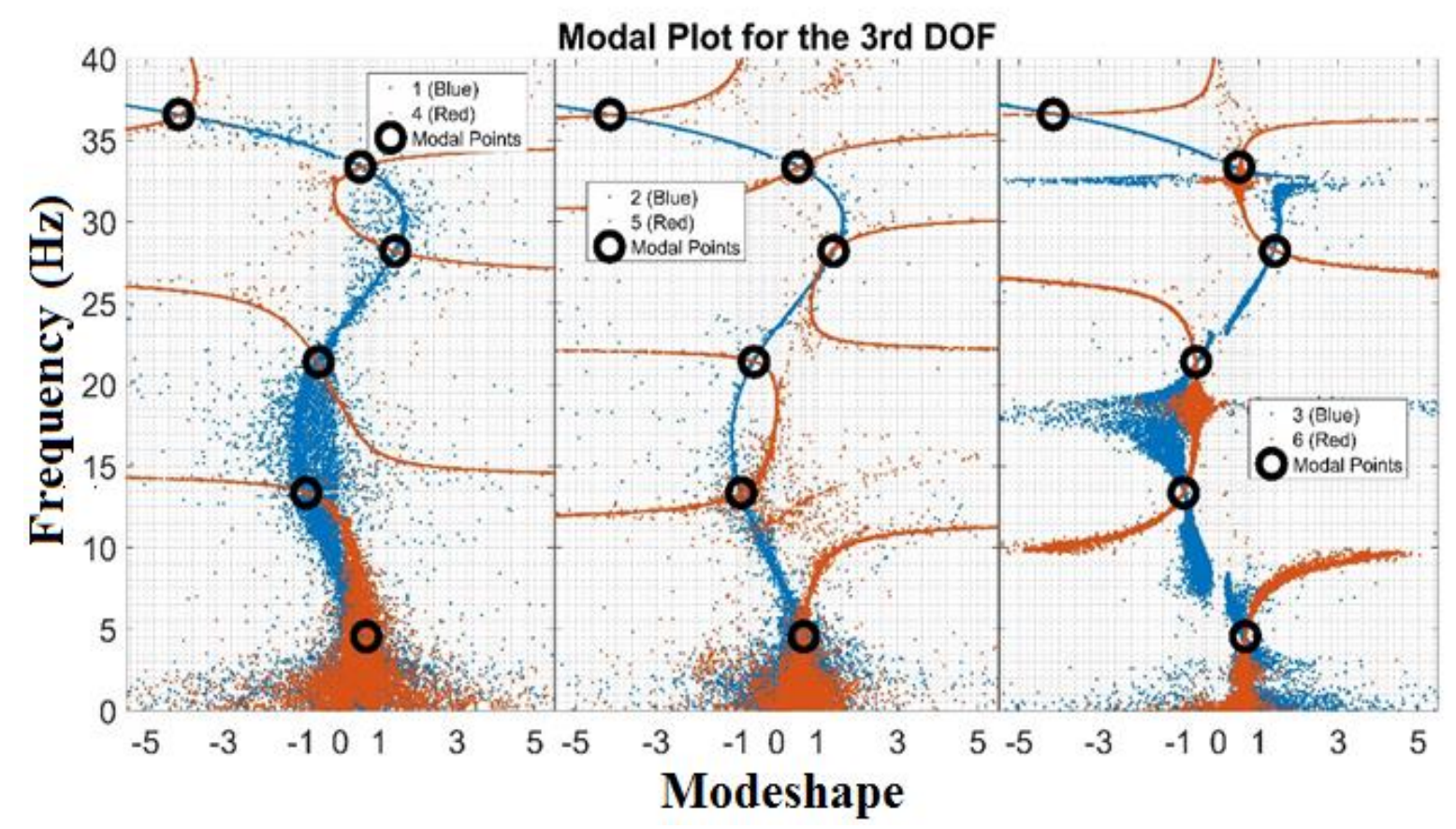

Figure 4. Modal plot for the 3rd DOF for different input force configuration couples.

In this study, it was stated that some modes cannot be driven sufficiently according to the force, and detecting damage with modes that cannot be driven sufficiently will cause the healthy structure to be detected as a damaged structure. To illustrate this phenomenon, an example is shown in Fig. 5, in which the modal plots are presented in the same way as in Fig. 4. Unlikely, it is aimed to show only the modal zones related to the 2 nd modal point of the 5 th DOF to better examine the modal plots. As can be seen in Fig. 4, when force is applied from all DOF except the 5th DOF, it is seen that the modal zones are 
very close to the modal points. When force is exerted by the 5 th freedom, the 5 th degree of freedom $2 \mathrm{nd}$ mode shape value will be determined with approximately 5-7\% error. Note that in this part, average values were calculated with 1 cluster $(\mathrm{k}=1)$ in 2 dimensions (both the natural frequencies and the mode shapes) according to sufficiently small frequency ranges, thus completely eliminating noise-induced modes.

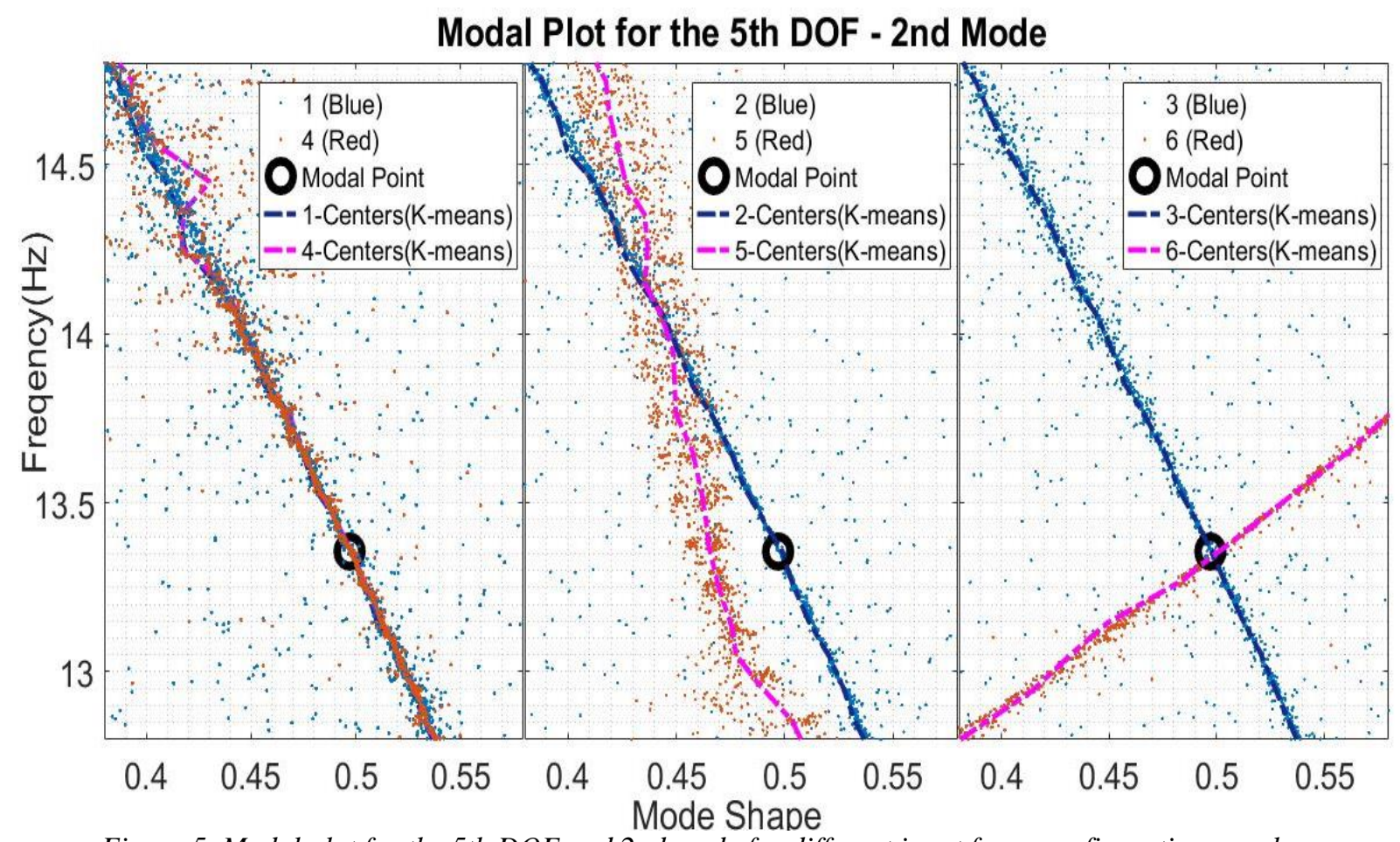

Figure 5. Modal plot for the 5th DOF and 2nd mode for different input force configuration couples.

\subsection{The Shaker Position in Mode Excitation}

In the second case study, it was desired to investigate the position effect of the shaker without any vibration. Shaker applies white noise to the degrees of freedom (DOF) where it is placed. For this, a system with $15 \mathrm{DOF}$ is examined. The shaker is placed in 2 different positions, namely the 4th and 10th DOFs, and the ability of the shaker to activate all modes is investigated. In Figs. 6-12, two subgraphs are given in each figure according to the position of the shaker. Accordingly, for the analyzed DOF, while the shaker position was at the 4th degree of freedom, the first six modes are properly driven for all DOFs. However, while the shaker was at the 10th DOF, the 2 nd and 5 th modes could not be activated in the first nine DOFs. But all other DOFs (10-15) could be properly driven. In this case, it is seen that the position of the shaker is also important. 


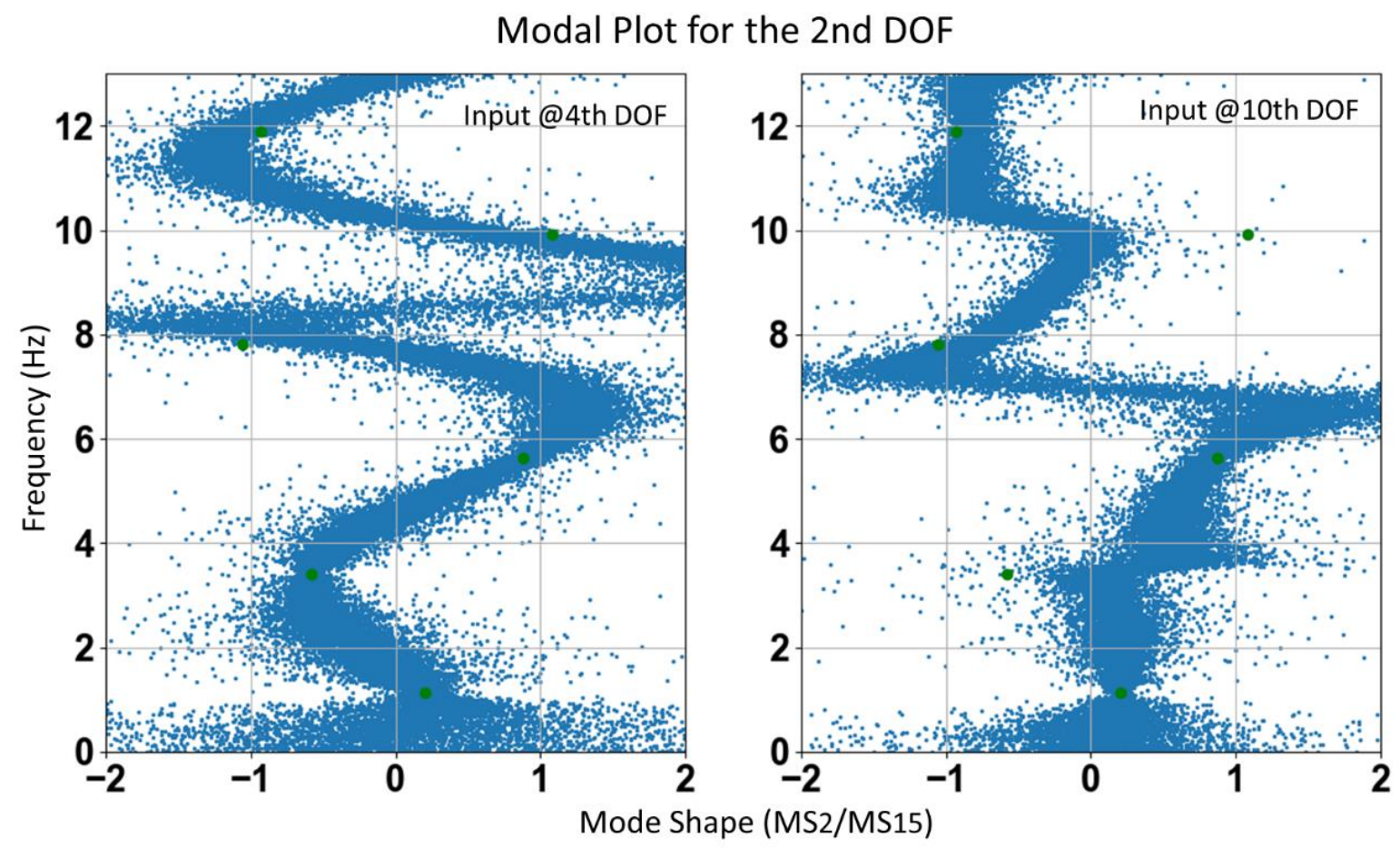

Figure 6. Shaker location comparison for the 2nd DOF.

Modal Plot for the 4th DOF

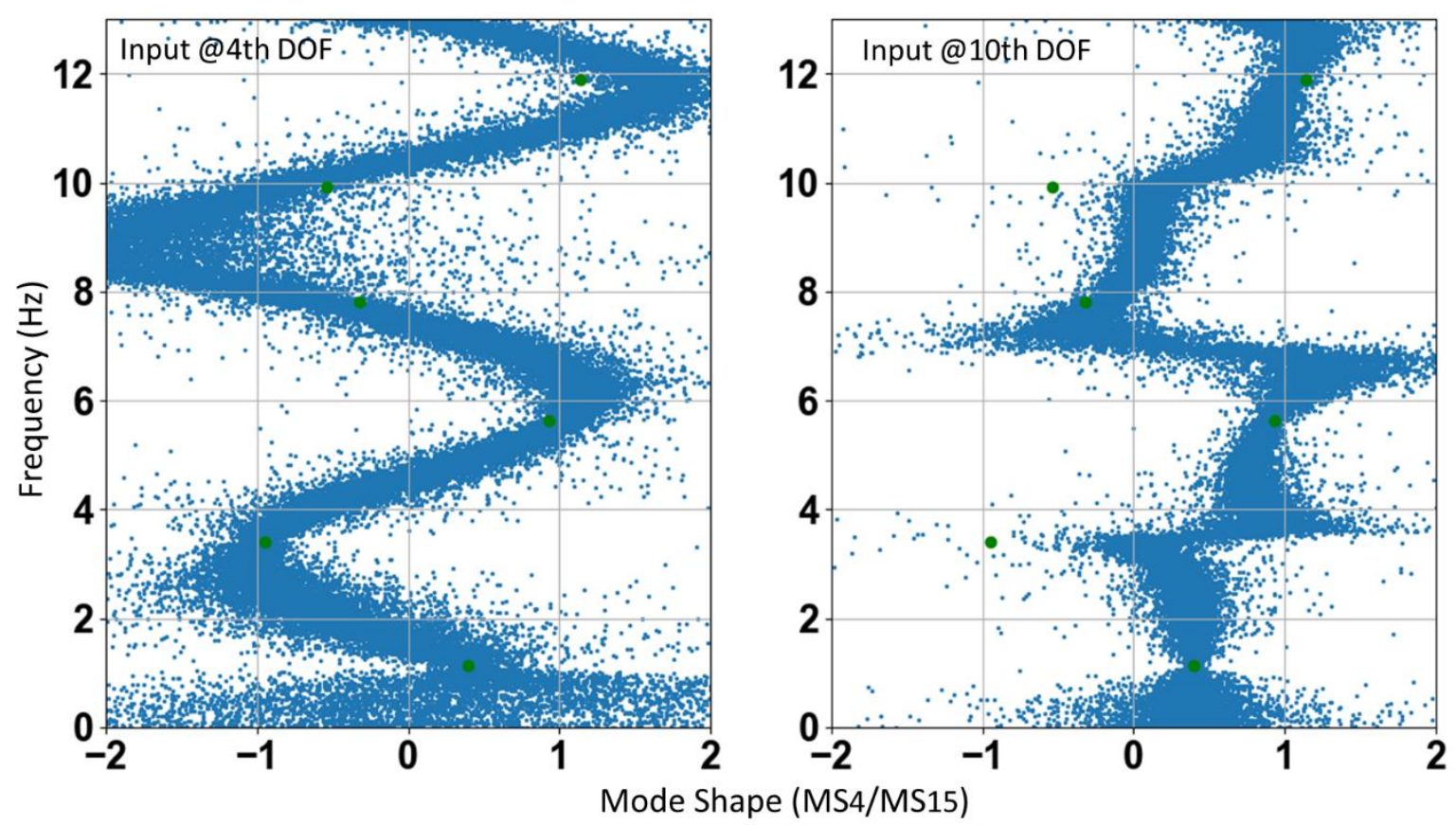

Figure 7. Shaker location comparison for the 4th DOF. 


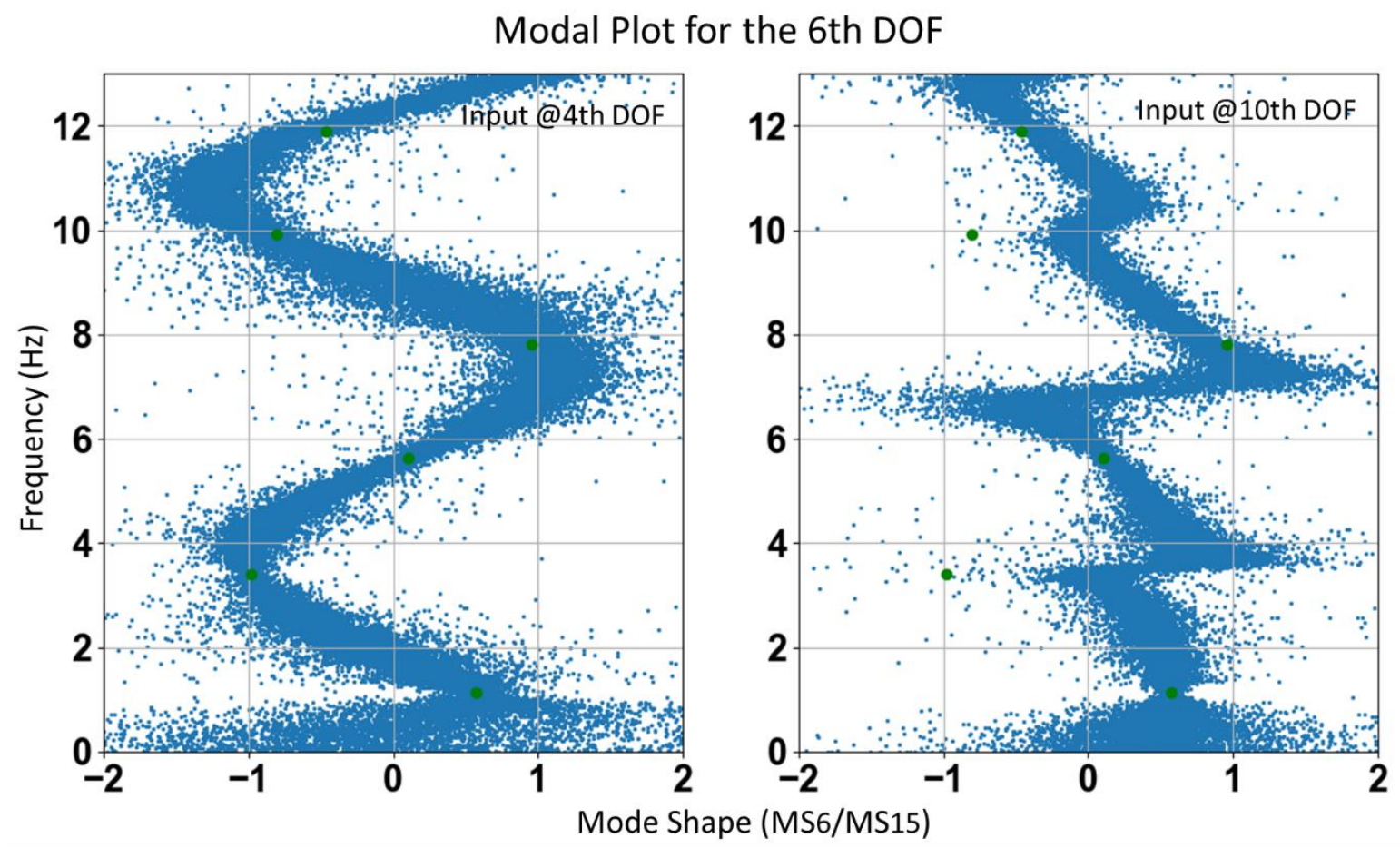

Figure 8. Shaker location comparison for the 6th DOF.

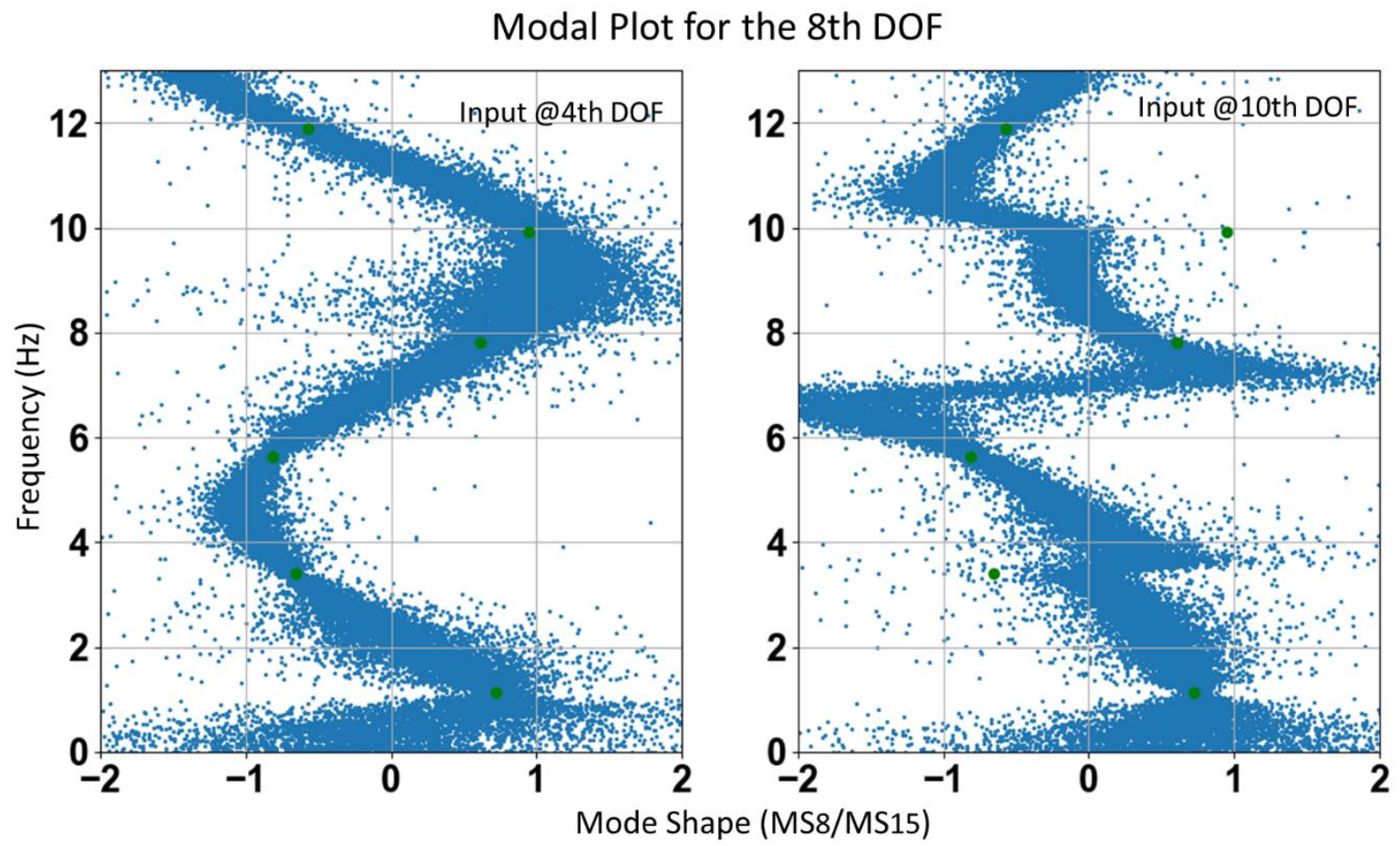

Figure 9. Shaker location comparison for the 8th DOF. 


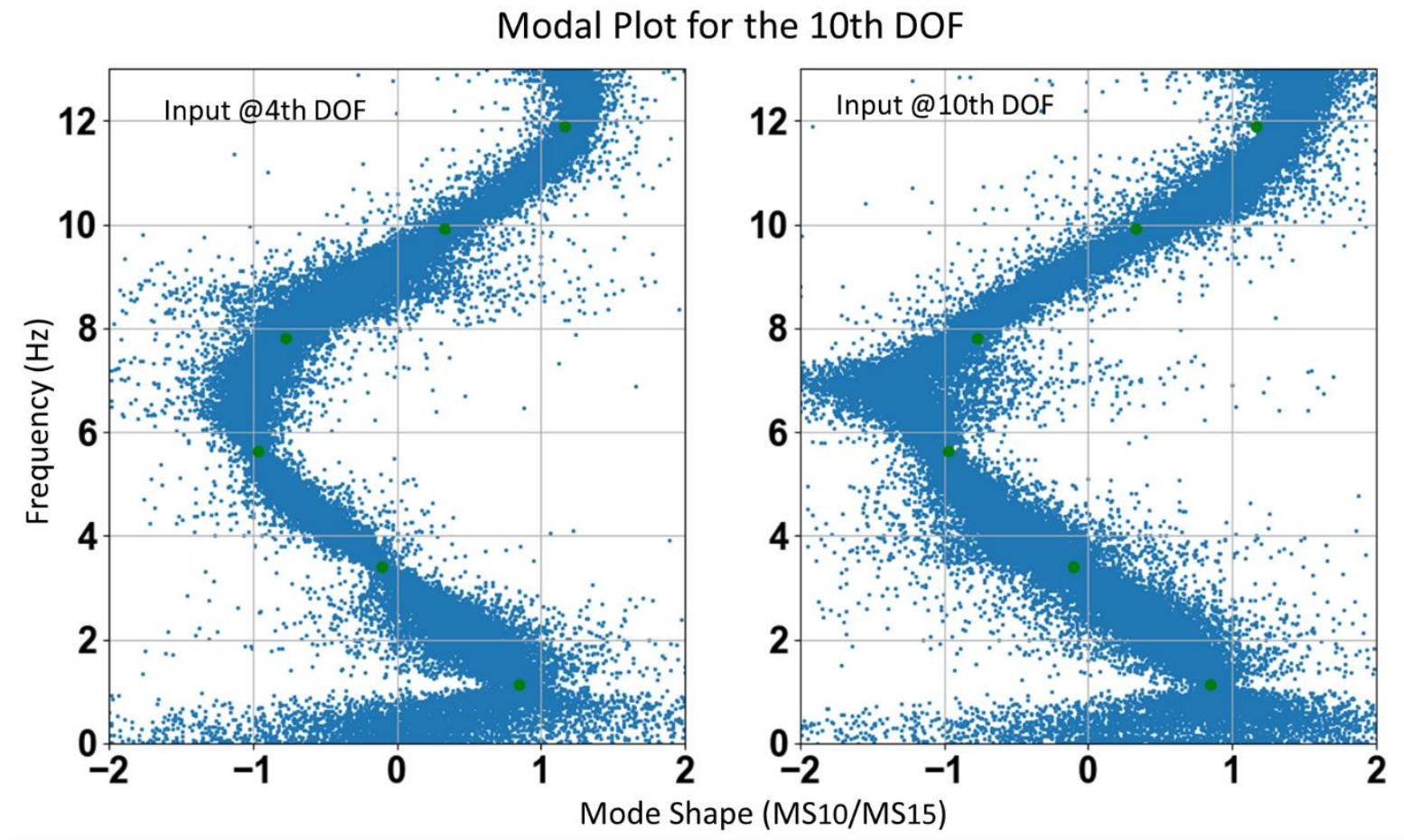

Figure 10. Shaker location comparison for the 10th DOF.

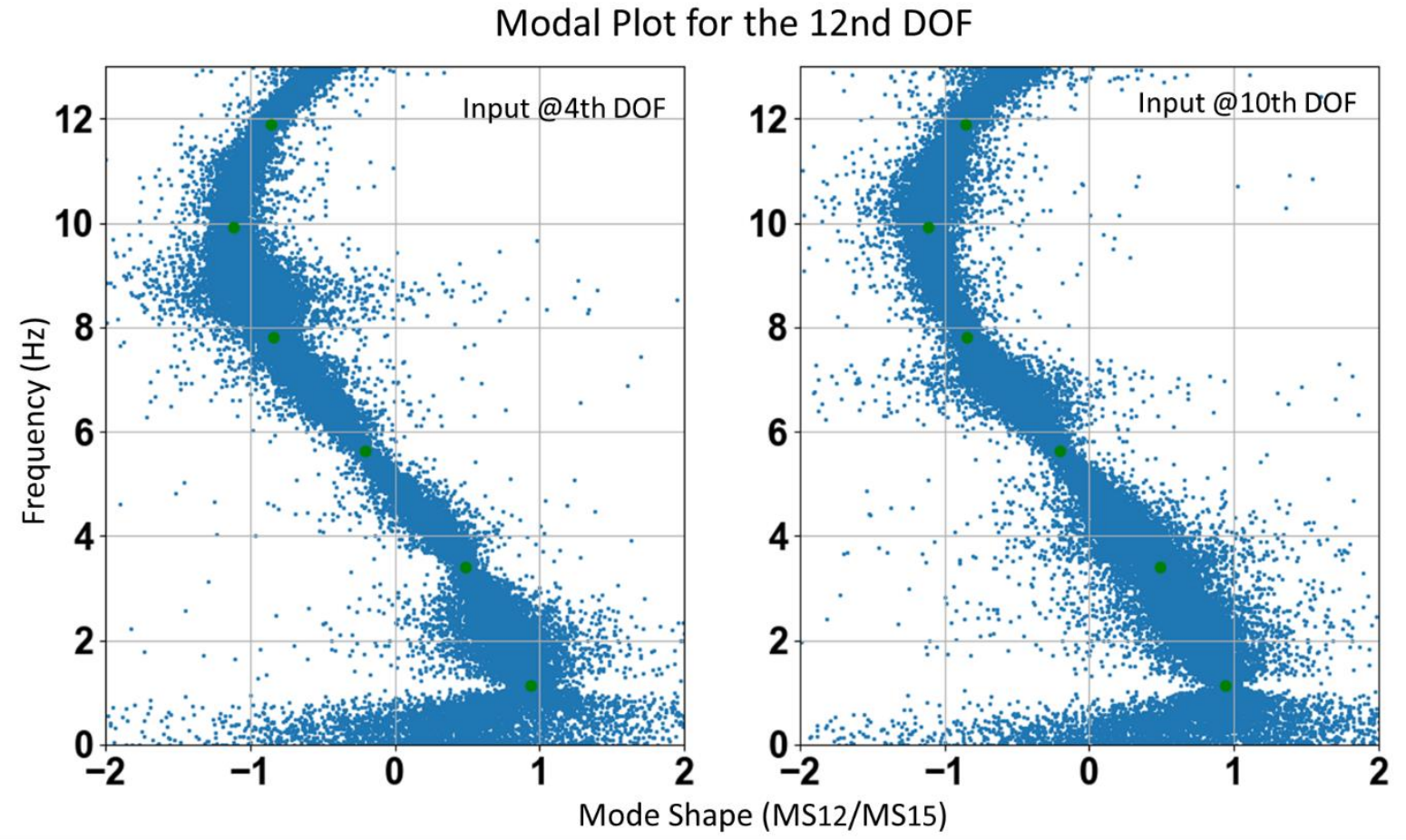

Figure 11. Shaker location comparison for the 12th DOF. 


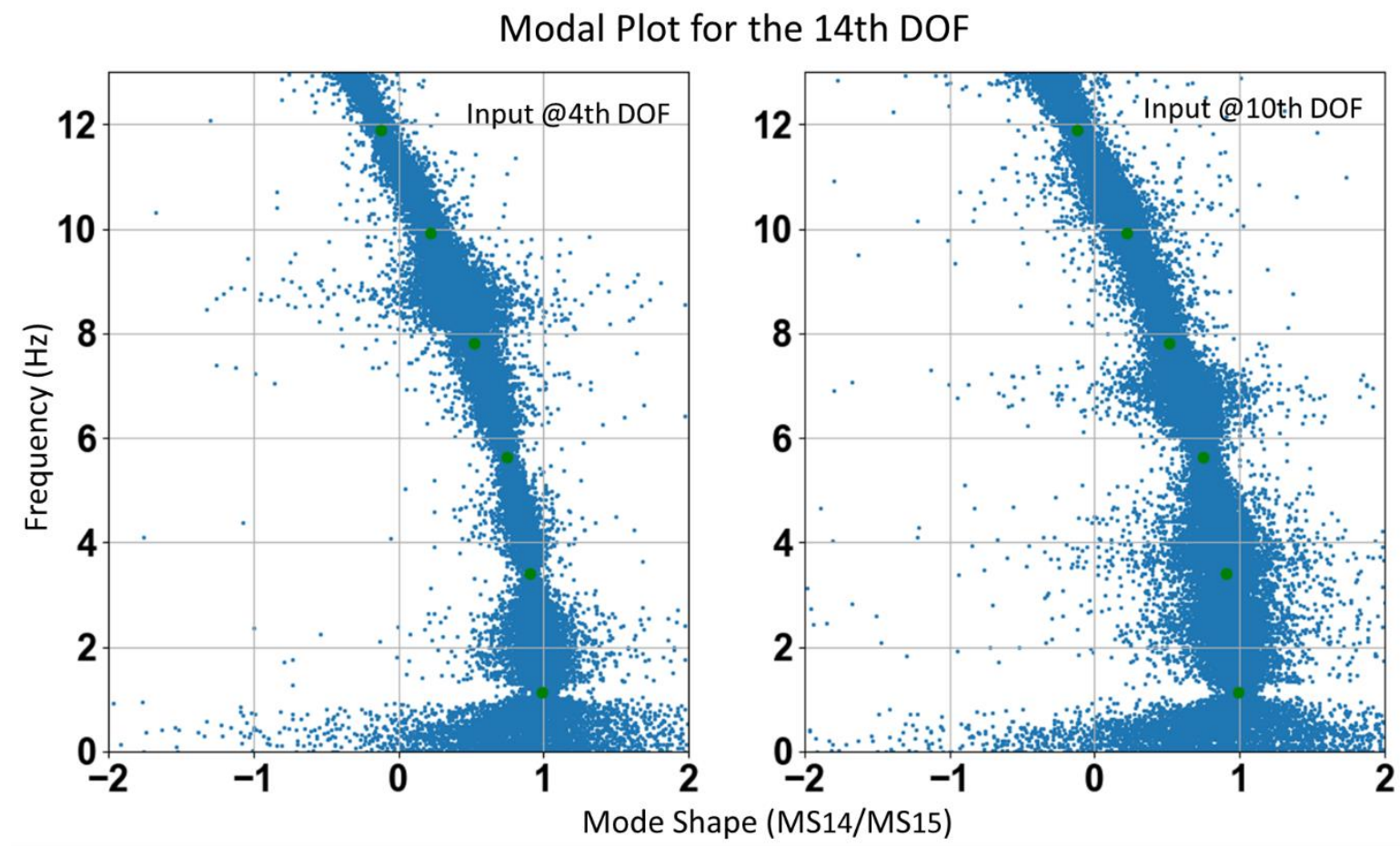

Figure 12. Shaker location comparison for the 14th DOF.

\subsection{Case Study III: Damping Effect}

In the third case study, a different system whose features are given in Table 1 is used. The modal properties of a system with 5\% critical damping and an undamped system are expected to be very close to each other.

Table 1 Numerical Analysis Specifications.

\begin{tabular}{ll}
\hline Properties & Type/Value \\
\hline Number of DOFs & 15 \\
End Conditions & Fixed-Free \\
Spring Stiffness & $2.27 \mathrm{E} 8 \mathrm{~N} / \mathrm{m}$ \\
1st-14th DOF mass & $4530 \mathrm{~kg}$ \\
15th DOF mass & $2265 \mathrm{~kg}$ \\
Input DOF & 15 th DOF \\
Input Type & Ambient Vibration \\
\hline
\end{tabular}

Fig. 13 shows the modal plots of systems with 5\% critical damping and the undamped system for the 1 st DOF when the ambient force is exerted from the 15th DOF. For the undamped system, it is seen that the modal zones pass quite close to the modal points. However, when the damping is introduced to the system, it is seen that the modal zones move away from the modal points, especially from the 3rd Modal point and following modes. In this case, it is clearly seen that the modal properties of the system to be determined will express the system incorrectly. 


\section{Modal Plot:Damped and Undamped Systems (Comparison)}

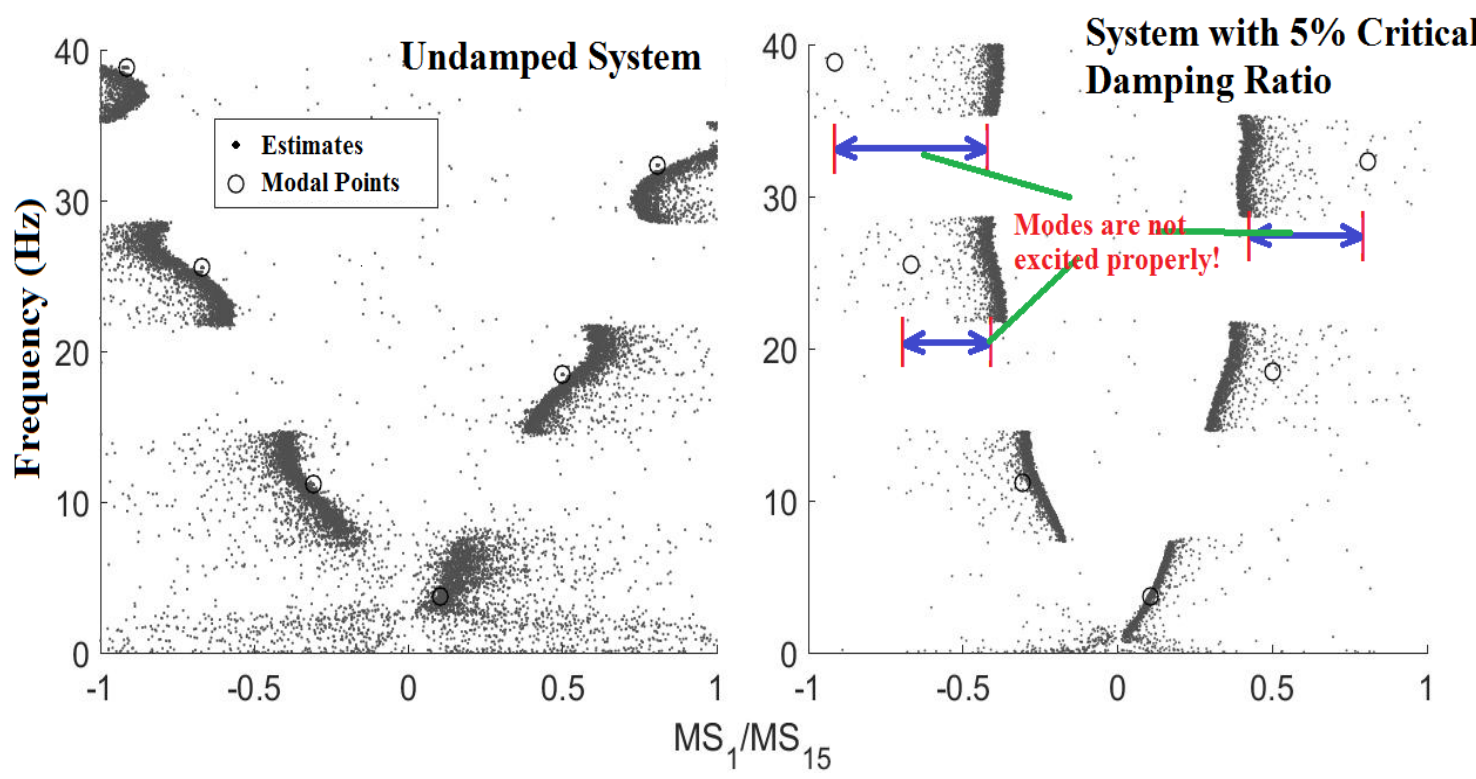

Figure 13. Modal Plot undamped and damped systems

\section{CONCLUSION}

In the literature, the modal plot method is used in system identification and damage detection and the purpose of this study is to show that it can also be used in the assessment of mode excitation energy. In cases where operational forces are not proper due to irregularities in the characterization of a structure, location of excitation, input frequency content to activate system mode in a certain frequency band, OMA methods are insufficient and to assess system properties shakers should be used and the system must be analyzed by using and OMAX methods. It is decided by looking at the frequency response function peaks to understand whether the use of a shaker is necessary, but as in the second case study, modal plots in a more systematic way allow us to make this decision more clearly. This decision is important because it is possible for the shaking structure to activate its mods while simultaneously damaging the structure. It is aimed to show how much the modes are excited under operational white noises by using modal plots through three case studies. In the case studies, modal plots are therefore a suitable tool for displaying mode excitation energy. Thus, the answer to the question about how much the energy harvested by environmental forces can drive the structural modes is sought with modal plots. It should be noted that if the mode in question is not sufficiently excited, it is interpreted as a harbinger of damage for an undamaged structure in the analysis using these modes.

\section{REFERENCES}

[1] Büyüköztürk, O, Yu, TY. Structural health monitoring and seismic impact assessment. In: The 5th National Conference on Earthquake Engineering; 26-30 May 2003: Cenkler Matbaas1, Bucharest, Romania, pp 1-6.

[2] Aktan, AE, Farhey, DN, Brown, DL, Dalal, V, Helmicki, AJ, Hunt VJ, Shelley, SJ. Condition assessment for bridge management. Journal of Infrastructure Systems 1996; 2(3): 108-117. DOI: 10.1061/(ASCE)10760342(1996)2:3(108).

[3] Fujino, Y, Siringoringo, D. Strategies for structural health monitoring of bridges: Japan's experience and practice. In: Martinez JM, American Environmentalism: Philosophy, History, and Public Policy. New York, United States: Routledge, 2013, pp. 15-20.

[4] Güney, D. Ekim 2011 Van Depremi Teknik İnceleme Raporu [Van earthquake technical investigation report] Yıldız Technical University, İstanbul, 2011. 
[5] Williamson, AL, Newman, AV. Suitability of open-ocean instrumentation for use in near-field tsunami early warning along seismically active subduction zones. Pure and Applied Geophysics, 2019; 176(7): 3247-3262. DOI: $10.1007 / \mathrm{s} 00024-018-1898-6$.

[6] FEMA. Safe rooms for tornadoes and hurricanes: Guidance for community and residential safe rooms, Washington, DC, 2015

[7] Sumitro, S, Wang, ML. Structural Health Monitoring System Applications in Japan. In: Ansari F., Sensing Issues in Civil Structural Health Monitoring, Dordrecht, Netherlands: Springer, 2005, pp. 495-504.

[8] Chan TH, Thambiratnam DP. Structural health monitoring in Australia. Hauppauge New York, United States: Nova Science Publishers, 2011.

[9] Çaktı, E, Şafak, E. Structural Health Monitoring: Lessons Learned. In: Kasimzade, AA, Şafak, E, Ventura, CE, Naeim F, Mukai Y, Seismic Isolation, Structural Health Monitoring, and Performance Based Seismic Design in Earthquake Engineering, Cham, Switzerland: Springer, 2019, pp. 145-164.

[10] Chen, GW, Omenzetter, P, Beskhyroun, S. Operational modal analysis of an eleven-span concrete bridge subjected to weak ambient excitations. Engineering Structures 2017; 151: 839-860. DOI: 10.1016/j.engstruct.2017.08.066.

[11] Abé, M, Fujino, Y. Monitoring of long-span bridges in Japan. Proceedings of the Institution of Civil Engineers-Civil Engineering 2017; 170(3): 135-144. DOI: 10.1680/jcien.16.00002.

[12] Hester, J, Prabhu, S, Atamturktur, S, Sorber, J. Remote and wireless long-term vibration monitoring of historic monuments. Procedia engineering 2017; 199: 3302-3307. DOI: 10.1016/j.proeng.2017.09.416.

[13] Compán, V, Pachón, P, Cámara, M, Lourenço, PB, Sáez, A. Structural safety assessment of geometrically complex masonry vaults by non-linear analysis. The Chapel of the Würzburg Residence (Germany). Engineering Structures 2017; 140: 1-13. DOI: 10.1016/j.engstruct.2017.03.002.

[14] Lorenzo, GWF, Mercerat, D, d'Avila, MPS, Bertrand, E, Deschamps, A. Operational modal analysis of a high rise rc building and modelling. In IOMAC'15-The 6th International Operational Modal Analysis Conference; 12-14 May 2015: Gijon, Spain, pp. 1-10.

[15] Juul, M, Balling, O, Brincker, R. Operational Modal Analysis on Wind Turbine Hub. In: Mains M, Dilworth BJ, Topics in Modal Analysis \& Testing. Cham, Switzerland: Springer, 2019. pp. 69-77.

[16] Kirschneck, M, Rixen, DJ, Polinder, H, van Ostayen, R. In-Situ Experimental Modal Analysis of a DirectDrive Wind Turbine Generator. In: De Clerck J, Experimental Techniques, Rotating Machinery, and Acoustics. Cham, Switzerland: Springer, 2015. pp. 157-165.

[17] Nord, TS, Kvåle, KA, Petersen, ØW, Bjerkås, M, Lourens, EM. Operational modal analysis on a lighthouse structure subjected to ice actions. Procedia engineering 2017; 199: pp. 1014-1019. DOI: 10.1016/j.proeng.2017.09.268.

[18] Friedland B. Control system design: an introduction to state-space methods. Mineola, New York, United States: Bernard Friedland Dover Publications, 2012.

[19] Yang, JN. Application of optimal control theory to civil engineering structures. J Eng Mech Div-ASCE 1975; 101(6): 819-838. DOI: 10.1002/stc.334.

[20] Peeters B. System identification and damage detection in civil engeneering. PhD Thesis, Katholieke Universiteit Leuven, Belgium, 2000.

[21] Ren WX and Zong ZH. Output-only modal parameter identification of civil engineering structures. Structural Engineering and Mechanics 2004; 17(3-4): pp. 429-444. DOI: 10.12989/sem.2004.17.3_4.429.

[22] Zonzini, F, Malatesta, MM, Bogomolov, D, Testoni, N, Marzani, A, De Marchi, L. Vibration-Based SHM With Upscalable and Low-Cost Sensor Networks. IEEE Transactions on Instrumentation and Measurement 2020; 69(10): pp. 7990-7998. DOI: 10.1109/TIM.2020.2982814.

[23] Fu, Z, He, J. Overview of modal analysis. In: He, J, Fu, ZF, Modal analysis, Butterworth-Heinemann, Oxford, United Kingdom: Elsevier, 2001, pp. 1-11. DOI: 10.1016/B978-0-7506-5079-3.X5000-1

[24] Rainieri, C, Fabbrocino, G. Automated output-only dynamic identification of civil engineering structures. Mechanical Systems and Signal Processing 2010; 24(3): 678-695. DOI: 10.1016/j.ymssp.2009.10.003.

[25] Alonso, R, Albizuri, J, Esparza, J. Application of model updating techniques to turbomachinery rotor components. Advances in Mechanical Engineering 2019; 11(7): 1-9. DOI: 10.1177/1687814019863941.

[26] Gomes, GF, Mendéz, YAD, da Cunha, SS. A numerical-experimental study for structural damage detection in CFRP plates using remote vibration measurements. Journal of Civil Structural Health Monitoring 2018; 8: 33-47. DOI: 10.1007/s13349-017-0254-3.

[27] Rao, SS. Mechanical Vibrations. Miami, United States: Prentice Hall, 2011.

[28] Rainieri, C, Fabbrocino, G. Automated output-only dynamic identification of civil engineering structures. Mechanical Systems and Signal Processing 2010; 24(3): 678-695. DOI: 10.1016/j.ymssp.2009.10.003.

[29] Reynders, E. System identification and modal Analysis in structural mechanics. PhD Thesis, Katholieke Universiteit Leuven, Belgium, 2009. 
[30] Reynders, E, Daan Degrauwe, D, Roeck, GD, Magalhães, F, Caetano, E. Combined experimental-operational modal testing of footbridges. Journal of Engineering Mechanics 2010; 136(6): 687-696. DOI: 10.1061/(ASCE)EM.1943-7889.0000119.

[31] Cauberghe, B, Guillaume, P, Verboven, P, Parloo, E, Vanlanduit, S. A combined experimental-operational modal analysis approach in the frequency domain. In: The 21st International Modal Analysis Conference (IMAC XXI); 3-6 February 2003: Kissemmee, Florida, USA, pp. 1-9.

[32] Pioldi, F, Salvi, J, Rizzi, E. Refined FDD modal dynamic identification from earthquake responses with SoilStructure Interaction. International Journal of Mechanical Sciences 2017; 127: 47-61. DOI: 10.1016/j.ijmecsci.2016.10.032.

[33] Tufan, T, Akalp, S. Modal plot-System identification and fault detection. Structural Control and Health Monitoring 2019; 26(5): e2347. DOI: 10.1002/stc.2347.

[34] McRAE DJ. K-means clustering using multivariate data. Classification Soc. Bull 1970; 2(2): 62.

[35] Perera, R, Torres, L, Ruiz, A, Barris, C, Baena, M. An EMI-Based Clustering for Structural Health Monitoring of NSM FRP Strengthening Systems. Sensors 2019; 19(17): 3775. DOI: 10.3390/s19173775.

[36].Hartigan JA, Wong MA. Algorithm AS 136: A k-means clustering algorithm. Journal of the Royal Statistical Society. Series C (Applied Statistics) 1979; 28(1): pp. 100-108. DOI: 10.2307/2346830. 